\title{
Original Research \\ Preparation of Samples for Determining Heavy Metals Fe and Mn in Vegetable Oils: a Comparison of Different Extraction Methods
}

\author{
Piotr Szyczewski ${ }^{\text {*, }}$ Marcin Frankowski ${ }^{1}$, Anetta Zioła-Frankowska ${ }^{2}$, Jerzy Siepak ${ }^{3}$, \\ Tomasz Szyczewski ${ }^{4}$, Paweł Piotrowski ${ }^{4}$
}

\author{
'Department of Water and Soil Analysis, Adam Mickiewicz University, Poznan, Poland \\ ${ }^{2}$ Department of Analytical Chemistry, Adam Mickiewicz University, Poznan, Poland \\ ${ }^{3}$ Hipolit Cegielski State College of Higher Education, Gniezno, Poland \\ ${ }^{4}$ Clinic of Oral Rehabilitation, Poznan University of Medical Sciences, Poland
}

Received: October 31, 2014

Accepted: June 9, 2015

\begin{abstract}
Vegetable oils belong to a large group of substances obtained from plants. They can be extracted from corn, olives, rape, or sunflower. The procedures of sample preparation applied at present are based on the ICPAES and ETAAS techniques, which comply with the heavy metal determination norm, are time-consuming, and require large amounts of chemical reagents - including organic solvents. The stage of preparation of vegetable oil samples for chemical analysis causes difficulties related to the extraction of sample ingredients to the solution, which can be determined by routine methods. During the extraction, there is a high risk of contaminating the sample or the analyte. The determination of the heavy metals iron and manganese in mineral oil samples is a major challenge for an analyst because of the sample properties and the conditions of the extraction procedure.

Due to the reasons stated above, our study aimed to select the appropriate conditions to facilitate the extraction process of oil samples and to simplify the procedure in terms of equipment requirements. Moreover, the developed procedure was compared with classical extraction methods in order to be applied in the determination of metals in oils. The paper also presents the concentration variability of $\mathrm{Cu}, \mathrm{Zn}, \mathrm{Pb}$, and $\mathrm{Cd}$, as well as $\mathrm{Fe}$ and $\mathrm{Mn}$ in the production process (from rapeseed to the final market product).
\end{abstract}

Keywords: heavy metals, rapeseed oil, sample preparation, FAAS

\section{Introduction}

Quality of food products is an important factor that provides the consumer with information about a potential danger posed by heavy metals, being the effect of a technological process. A significant increase in consumer awareness has boosted the creation of more and more rigorous criteria for permissible contents of harmful ingredients, which affects the introduction of these products to trade $[1,2]$

*e-mail: p.szyczewski@gmail.com
Vegetable oils are a large group of substances obtained from such plants as rape, corn, olives, sunflower, peanuts, and sesame, and the production of vegetable oils is soaring, reducing the popularity of animal fats. Vegetable oils are mixtures of esters of saturated and unsaturated fatty acids [3,4].

Polyunsaturated fatty acids are especially valuable nutrients, invaluable in human diet because, being the substrates of compounds vital for human life, they are not synthesized in the human body. It should be emphasized that about $80-90 \%$ of total content of heavy metals enters the human body through food [2]. 
In the group of heavy metals one can distinguish both the elements necessary for living organisms (microelements) and elements whose physiological role is unknown, and those that are "neutral" for plants, animals, and humans. Furthermore, metals that play the role of micro-elements in living organisms usually occur in trace amounts defined for specific species. Both the deficiency and excess of these metals has a harmful influence on living organisms, causing, among other things, disorders of the nervous system due to the tendency to accumulate in the brain or liver $[5,6]$.

The presence of heavy metals in vegetable oils may have a negative influence on the quality of oils, causing changes to their taste and smell. Such changes in oil quality, called "taste reversion," are caused by the occurrence of the following metals: $\mathrm{Fe}, \mathrm{Cu}, \mathrm{Cr}, \mathrm{Zn}$, and $\mathrm{Mn}$, which, through their ability to form radicals, facilitate the process of oxidation of fats [7].

The main source of contamination of oils with heavy metals is their direct migration from arable land to oil plants. Moreover, during technological processes, the enrichment of oils with heavy metals, such as Fe and Mn, can occur $[2,4]$. The factors that influence the content of heavy metals in plants also include individual properties of plants used in oil production. From among oil plants commonly used in the production of oil, rape is the one characterized by high accumulation properties [6]. Rapeseed oil is one of the 17 main fats produced in the world [8]. It is therefore justified to ensure proper monitoring of the production process and informing the consumer about harmful substances in food products.

The main legal act issued by the EU is Commission Directive (EC) No. 1881/2006 [9], which defines the highest permissible levels of some contaminants in food products. This act, however, does not regulate the permissible content of heavy metals $(\mathrm{Cd}, \mathrm{Cr}, \mathrm{Cu}, \mathrm{Ni}, \mathrm{Pb}, \mathrm{Zn}), \mathrm{Fe}$, or $\mathrm{Mn}$ in vegetable oils, which is worrying. The directive revoked the local binding legal regulations, which had regulated the permissible content of heavy metals in oils.

It is noteworthy that the determination of heavy metals in vegetable oils has always been a difficult task due to the stage of sample preparation for determination. The matrix contains large amounts of organic compounds, hence the necessity of extraction [8]. The oldest and still most common procedure is extraction in a Soxhlet apparatus, where benzene, diethylic ether, or chloroform are used as solvents. The disadvantage of this method is the fact that it is not recommended for the extraction of semi-solid samples. In the case of oil extraction it is therefore necessary to use a special paper filter that prevents the extract from oil contamination. In practice, it is difficult and often leads to the matrix effect. It can also be assumed that with such a difficult matrix, rich in fats, carbohydrates and proteins, at least one of the following processes should be used: microwave mineralization, increased pressure, incineration, and dissolution in acid. Taking these four methods into account, four basic groups of methods of preparing vegetable oil samples can be distinguished in the determination of heavy metals $[7,10-15]$ :

\section{Dry Mineralization}

The basic problem during the mineralization of an oil sample is its oily texture, containing a large amount of water and other volatile solvents, as well as the ignition temperature amounting to approximately $300^{\circ} \mathrm{C}$, depending on the source of oil origin. The method involved time-consuming vaporization of volatile solvents on a heating panel prior to sample mineralization.

Mineralization occurs in an open system, usually in a porcelain, quartz, or platinum melting pot, at $450-550^{\circ} \mathrm{C}$. The method's disadvantages include the loss of volatile ingredients, mechanical loss, the risk of secondary contamination, time-consuming procedures, and the two-stage process (incineration followed by dissolution in acid). Dry mineralization still remains a popular method of sample preparation. Many laboratories do not have sensitiveenough analytical equipment and the only way to obtain low determination limits is enlarging the analytical weight. The dry incineration technique allows for dissolving a 10$25 \mathrm{~g}$ sample, while at other techniques the weights are much smaller.

\section{Extraction by Solvent Aided by Microwave Radiation}

Wet mineralization is a large group of methods involving dilution of samples, but the complex matrix of vegetable oils and the necessity to vaporize the volatile solvents hampers effective individual application of these methods. The possibilities of analysis were broadened after coupling the methods with microwave systems (Microwave Assisted Extraction - MAE) [14]. Thanks to the fact that energy is supplied directly to the sample and the two-stage character is eliminated, the whole process is much shorter.

In microwave dilution, $2450 \mathrm{MHz}$ waves and 600$700 \mathrm{~W}$ power are usually applied. In food product analysis, two microwave systems can be distinguished: mineralization in closed pressure systems, and in open systems in atmospheric pressure. The first system is the most common one and it owes popularity to the speed of the process, limited use of reagents, limited risk of sample contamination, and loss of volatile ingredients. In turn, the open system is universal and is characterized by easy monitoring of microwave energy reaching the sample. The method disadvantages include, as in the case of other open systems, the risk of losing volatile analytes $[7,16]$.

\section{Accelerated Solvent Extraction}

The method of Accelerated Solvent Extraction (ASE) is a modern approach to sample preparation. It is based on the use of solvents at high temperature $\left(50-200^{\circ} \mathrm{C}\right)$ and pressure (10-14 Mpa), which allows for a significant increase in extraction process efficiency. The increased temperature may cause the elimination of a strong relationship between the analyte and sample matrix. With the use of Van der Waals forces and hydrogen bonds, the temperature also decreases the viscosity of organic solvents. This allows for 
better extraction between matrix particles, which results in higher extraction efficiency through the kinetics of solving processes and in the desorption of metals from the matrix. High pressure during extraction allows for the use of solvents in the liquid state above their boiling temperature. This enables the extraction of analytes in the matrix gaps, whose extraction by classic method poses difficulties. This method is especially useful in the preparation of vegetable oil samples due to the possibility to extract highly humid samples. The ASE method uses the same solvents as traditional extraction methods. However, their use is much more efficient. Therefore, the amount of solvent used per sample is much smaller [7].

\section{Supercritical Fluid Extraction}

The most common method used in the analysis of environmental and food samples is supercritical fluid extraction (SFE) [18]. In this method, supercritical fluid is the solvent. The supercritical state is extremely advantageous in terms of extraction as the value of diffusion coefficient is higher than in the case of a liquid solvent, and the viscosity is much lower and its value is close to gas viscosity.

Our paper aims to:

1) develop the procedure of preparing vegetable oil samples for determining $\mathrm{Cd}, \mathrm{Cu}, \mathrm{Pb}, \mathrm{Zn}, \mathrm{Fe}$, and $\mathrm{Mn}$ based on the above-mentioned methods;

2) select the appropriate extraction conditions for time and temperature, as well as the number and type of reagents;

3) determine the occurrence variability of heavy metals in seed during particular stages of the technological process.

The concentration of metals in oil plants and, in consequence, in their production stages, depends on many factors such as the type and species of plants, type of soil they are grown in, the degree of anthropogenic pressure they are subjected to, and fertilization and hydrological conditions (irrigation) [17, 18]. Additional and very important sources of metals are contaminants in food products originating from the processing in the equipment used in technological production processes, as well as vessels, containers, and packaging in which the food is stored and transported.

The influence on the degree of absorption of heavy metals by the human body from food also depends on the treatment of vegetable material prior to consumption or processing. For instance, washing, cleaning, or technological activities such as blanching and cooking reduce contamination by food with heavy metals [2]. Moreover, despite knowledge about the scope of heavy metal influence on the quality of oil, the concentration of metals is not included in the main parameters defining oil quality.

Basic parameters that determine oil quality include oxidation stability, peroxide and iodine number, content of phosphorus and free fatty acids, and spectrophotometric color. Iron is the metal meeting this group of parameters as it occurs in oils marked by the highest density (in comparison with other analyzed metals) and it is the "reference value" for a group of metals [18]. The minor significance of metals in the production process may increase the risk of material contamination with metals on a technological line. Due to the above-mentioned factors, the results should be discussed based on technological processes accompanying the production of rapeseed oil.

Raw pressed oil (fraction 1) is obtained by grinding rapeseed and roasting the mash, which is then humidified and conditioned. The increased temperature of raw material is favorable for the decrease of metal content. The destruction of tissue structure allows for the first extraction of oil during hot pressing in worm presses. The byproduct of the oil processing, including its further stages, are decoctions and residues. It should be underlined that during the production process toxic substances (not only heavy metals) are transferred to decoctions and residues. These, in turn, may be used in the production of fodder, posing an intermediate threat to animals and - through their products - to the consumer [7].

Another stage, the process of oil extraction, involves its multiple rinsing from seeds using the solvent (hexane). After the solvent is distilled, the extraction oil is produced before de-mudding (fraction 2). Neutral pressed oil (fraction 3) is marked by a lower concentration of metals in comparison to fraction 2. Obtaining this fraction involves oil hydration, removal of protein slime and phosphatides, and de-acidification using nitrogen hydroxide.

Whitening (de-coloring, or fraction 4) is aimed at the removal of pigments, such as chlorophyll, anthocyains, and carotenoids, which give the oils their dark color. This refers especially to the chlorophyll pigments which, apart from the dark color, accelerate oil oxidation. This process additionally removes polar substances (phospholipids and soaps) remaining after the process of de-acidification. The temperature applied when obtaining oil from raw material also affects the pigmentation of oils. In the process of de-coloring, whitening soil, active carbon, or aluminum oxide are used in order to absorb the given polar substances. The whitening is conducted at increased temperatures. The whitening soil is then separated by filters.

Deodorization is the final stage of oil refining, and it gives the product the final quality of refined oil. The process removes from the oil the substances responsible for unpleasant smell and taste, such as lower fatty acids, aldehyde and ketons, hydrocarbon, and sulfur compounds. The separation of these substances requires the use of distillation with water vapor under reduced pressure, as the boiling temperature of these compounds is $200-300^{\circ} \mathrm{C}$. As a result of these processes, production fraction 5 is obtained, which is the final product, ready for consumption.

\section{Materials and Methods}

\section{Samples}

Heavy metals and Fe and Mn were determined in samples that were semi-products obtained directly from the producer. Each sample was a different fraction, complying with the producer's technology. The samples obtained from the producer were stored in plastic containers (PP), in a 
shaded place, at room temperature. The samples of the following oils were analyzed: pressed raw oil (fraction 1), extraction oil before de-mudding (fraction 2), pressed neutral oil (fraction 3), pressed whitened oil (fraction 4), and pressed refined oil (fraction 5). Two independent series from particular production series were used in the study.

\section{Sample Preparation Procedure}

The optimization of oil sample preparation for chemical analysis involved reducing the time of sample preparation for determining and selecting the appropriate extraction temperature and amount of reagents. For comparison, some samples were prepared according to classical and simple extraction methods.

\section{Incineration (Procedures S1, S2, S3, S4)}

The procedure is based on the process of incineration and was developed by the research team of the authors of this paper. The incineration procedure was conducted for each series in different reaction vessels. In the first series a porcelain melting pot was used (S1), and in the second one a platinum pot (S1). The weight $-5 \mathrm{~g}$ in the first series and $10 \mathrm{~g}$ in the second - was placed in the reaction vessel and vaporized in a muffle furnace until total vaporization occurred ( $3 \mathrm{~h}$ ). The sample was then incinerated in the muffle furnace at $420^{\circ} \mathrm{C}$ (total incineration occurred after $1 \mathrm{~h}$ ). The incinerated sample was dissolved in nitric acid (V), vaporized on a heating panel, and subjected to the process of incineration in a muffle furnace. Using the nitric acid (V), the sample was transferred to the test-tube, hot-filtered, and filled to the capacity of $10 \mathrm{ml}$ with deionized water. The sample prepared in this way was ready for determinations.

The procedures of preparing samples S3 and S4 are modified versions of the procedure applied for samples S1 and $\mathrm{S} 2$ :

- S3: $10 \mathrm{~g}$ samples from fractions 1-5 were vaporized in a muffle furnace in a porcelain melting pot. Total vaporization occurred after 3 hours. The sample was then incinerated in a muffle furnace at $420^{\circ} \mathrm{C}$, with total incineration occurring after one hour. Using nitric acid (V), the sample was transferred to a test-tube, hot-filtered, filled to the capacity of $10 \mathrm{ml}$ with deionized water, and determined using the FAAS technique.

- S4: $10 \mathrm{~g}$ samples from fractions 1-5 were vaporized in a muffle furnace in a porcelain melting pot. Total vaporization occurred after three hours. The sample was then incinerated in a muffle furnace at $420^{\circ} \mathrm{C}$ for 30 minutes and $550^{\circ} \mathrm{C}$ for another 30 minutes. Using nitric acid (V), the sample was transferred to a test-tube, hot-filtered, filled to the capacity of $10 \mathrm{ml}$ with deionized water, and determined using the FAAS technique.

\section{Shaking}

A $10 \mathrm{~g}$ sample of oil from fractions 1-5, series I was placed in a measuring tube and $20 \mathrm{ml}$ of nitric acid (V)
Table 1. Measurement conditions for atomic absorption spectrometer (Varian SpectrAA 20 Plus).

\begin{tabular}{|c|c|c|c|}
\hline Element & Wavelength $[\mathrm{nm}]$ & Slot width $[\mathrm{nm}]$ & Flame \\
\hline $\mathrm{Cu}$ & 324.8 & 0.5 & \\
\cline { 1 - 3 } $\mathrm{Zn}$ & 213.9 & 0.2 & \multirow{2}{*}{ air - acetylene } \\
\hline $\mathrm{Mn}$ & 279.5 & 0.2 & \\
\hline $\mathrm{Fe}$ & 248.3 & 0.2 & \\
\hline $\mathrm{Pb}$ & 283.3 & 0.5 & \\
\hline $\mathrm{Cd}$ & 228.8 & 0.5 & \\
\hline
\end{tabular}

were added. The samples were shaken using a rotation shaker for $30 \mathrm{~min}$. (sample W1), $60 \mathrm{~min}$. (sample W2), $120 \mathrm{~min}$. (sample W3), $240 \mathrm{~min}$. (sample W4), $20 \mathrm{~h}$ (sample W5) and $2 \mathrm{~h}$ (sample W6). After shaking, the samples were moved to a separator. Following the separation of phases, the acid phase was filtered into the test-tube. In total, 30 samples were prepared using the shaking procedure $(\mathrm{W})$. The samples prepared in this way were ready for determinations.

\section{Mixing}

A $10 \mathrm{~g}$ sample of oil from fractions 1-5, series I was placed in a conical tube and $20 \mathrm{ml}$ of nitric acid (V) were added. The samples were mixed at $40^{\circ} \mathrm{C}$ using a magnetic mixer for $30 \mathrm{~min}$. (sample M1), $60 \mathrm{~min}$. (sample M2), 120 min. (sample M3), and $240 \mathrm{~min}$. (sample M4) under a reverse cooler. After mixing, the samples were moved to a separator. Following the separation of phases, the acid phase was filtered into a test-tube. In total, 20 samples were prepared using the mixing procedure $(\mathrm{M})$.

\section{Instrumentation}

The concentrations of heavy metals Fe and Mn were determined using atomic adsorption spectrometry with flame atomization (F-AAS) using a SpectrAA 20 Plus spectrometer produced by Varian (Varian, Australia). The measurement parameters are given in Table 1.

The following instruments were applied in the sample preparation stage: a Nabertherm L5/C6 muffle furnace with maximum power of $2.4 \mathrm{~kW}$, a heating panel with maximum power of $2.8 \mathrm{~kW}$, a rotation shaker designed at the Department of Water and Ground Analysis, and a magnetic mixer with maximum power of $0.8 \mathrm{~kW}$ (with heating function).

\section{Reagents}

The following Suprapure reagents were used in the study: $65 \% \mathrm{HNO}_{3}$ (Merck, Darmstadt, Germany) and water deionized by Millipore apparatus with $>18.6 \mathrm{M} \Omega$ resistance (Millipore, France). 
Table 2. Concentrations of heavy metals, $\mathrm{Fe}$, and $\mathrm{Mn}$ in rapeseed (fraction 0 ).

\begin{tabular}{|c|c|c|c|c|c|c|c|}
\hline Fraction & Sample & $\mathrm{Cu}$ & $\mathrm{Zn}$ & $\mathrm{Mn}$ & $\mathrm{Fe}$ & $\mathrm{Pb}$ & $\mathrm{Cd}$ \\
\hline \multirow{2}{*}{0} & $0-\mathrm{S} 1$ & 1.23 & 22.66 & 26.60 & 58.03 & 1.20 & 0.37 \\
\cline { 2 - 9 } & $0-\mathrm{S} 2$ & 0.76 & 24.84 & 22.04 & 64.82 & 1.43 & 0.31 \\
\hline
\end{tabular}

\section{Results and Discussion}

The discussion involves the comparison of three methods of sample preparation: incineration, shaking, and mixing. In the method using incineration, the application of two types of melting pots aimed to investigate the recurrence of results in the course of oil production and to check if metals are not rinsed out to the laboratory sample from the walls of a porcelain melting pot. In general, simple methods involving the dilution of the sample in highly oxidizing acids were not used in the extraction from such difficult semi-solid matrices as oils and fats. That is why the authors considered this research topic worth studying and decided to investigate whether classical methods can be used in methods of metal determination in oils. As a result, procedures S3 and S4 were compared with the methods dedicated for vegetable oils: S1 and S2, optimized by the authors.

Table 2 presents the study results for rapeseed samples obtained from the producer. The material was preliminarily cleaned and transferred for analysis without any other technological procedures. Incineration procedures S1 and S2 were applied in the study.

Table 3 presents the study results obtained for vegetable oil samples for all methods based on the suggested analytical procedures. In order to maintain the unambiguity of the table, maximum and minimum concentration values were given for samples prepared by shaking (W) and mixing (M).

Two theses were presented in the study:

1) the highest concentrations of heavy metals and $\mathrm{Fe}$ and $\mathrm{Mn}$, and at the same time the highest effectiveness of extraction, were expected in full incineration procedures S1 and S2, developed especially for the vegetable oil samples;

2) in the case of classical methods of dissolution in acid shaking (W) and mixing (M) - a positive relationship between extraction time and its effectiveness was expected. Fig. 1 presents the variability of metal concentration depending on the stage of oil production.

The highest concentrations of each metal were observed in rapeseed samples. This can be related to the low degree of processing of the material, which was only preliminary cleaned before further stages of the production cycle.

Highest concentrations of iron were determined in rapeseed: series I (58.03 mg/kg) and series II (64.82 mg/kg). Moreover, high concentrations of manganese and zinc were found: S1 $26.60 \mathrm{mg} / \mathrm{kg}$ and S2 $22.04 \mathrm{mg} / \mathrm{kg}$. Relatively high concentrations of lead were observed: S1 $1.20 \mathrm{mg} / \mathrm{kg}$ and S2 $1.43 \mathrm{mg} / \mathrm{kg}$, as well as of cadmium: $0.37 \mathrm{mg} / \mathrm{kg}$ for $\mathrm{S} 1$ and $0.31 \mathrm{mg} / \mathrm{kg}$ for $\mathrm{S} 2$, which is related to the accumulation of these heavy metals in rapeseed and migration from soils.
Raw pressed oil (fraction 1) contains lower concentrations of metals. Investigating the variability of metal concentrations in the subsequent stages of production, two groups of metals can be distinguished. One group is characterized by a minor difference between maximum and minimum values of concentration for each procedure in this and subsequent fractions. Zinc and cadmium belong to this group. In turn, a major difference between these values was found for copper and manganese. The results were presented in Fig. 1.

The obtained raw oil is to a large extent purified of metals and the decrease in concentration of each determined metal was observed. Attention should be drawn to significant discrepancies in metal concentrations in samples S1 and S2, which were prepared in accordance with procedures dedicated for vegetable oils that have been developed by the authors. The results obtained for Fe, whose presence dominates in the sample, were compared with the data given by Radziemska et al. (2.34 mg/kg) [18].

Sample S1 contained $3.38 \mathrm{mg} / \mathrm{kg} \mathrm{Fe}$, and sample S2, prepared in a platinum melting pot, contained $0.92 \mathrm{mg} / \mathrm{kg}$. Such large differences in concentrations are understandable as they occur in the introductory stage of processing the material, from which many contaminants were not removed. In the samples prepared by shaking (W) and mixing (M), a relationship was observed between the time of mixing and metal concentration. The maximum concentration values obtained by shaking are from $15 \%$ to $400 \%$ higher than in the case of minimum concentrations, and the maximum values were observed for longer shaking and mixing. In addition, the temperature program applied during mixing increases the effectiveness of extraction to the concentrations of samples S1 and S2, developed for vegetable oils, whereby the difference between minimal and maximal values is smaller than in the case of shaking. A much lower effectiveness of extraction was observed in the case of samples S3 and S4. These are the samples prepared in accordance with procedures S1 and S2 developed by the authors, reduced by one incineration stage. The extraction effectiveness in S1 compared to S3 and S4 is from $10 \%$ to $2,000 \%$ higher, depending on the metal.

Oils obtained in the extraction process (fraction 2) are highly contaminated as the solvent extracts many other components besides oil. Furthermore, the increased temperature of the process accelerates metal extraction from the mesh along with oil. This results in increases in cadmium and lead concentrations. The difference between maximum and minimum concentrations while shaking (W) and mixing (M) is significantly reduced, although the effectiveness of extraction by shaking is still worse in comparison with mixing in raised temperatures. Very low concentra- 
Table 3. Concentrations of heavy metals, $\mathrm{Fe}$, and $\mathrm{Mn}$ in production fractions of rapeseed oil.

\begin{tabular}{|c|c|c|c|c|c|c|c|c|}
\hline Fraction* & Sample & & $\mathrm{Cu}$ & $\mathrm{Zn}$ & $\mathrm{Mn}$ & $\mathrm{Fe}$ & $\mathrm{Pb}$ & $\mathrm{Cd}$ \\
\hline \multirow{8}{*}{1} & $1-\mathrm{S} 1$ & & 0.40 & 1.7 & 0.51 & 3.38 & $<0.06$ & 0.08 \\
\hline & $1-\mathrm{S} 2$ & & 0.05 & 1.33 & 0.29 & 0.92 & 0.10 & $<0.01$ \\
\hline & $1-\mathrm{S} 3$ & & 0.02 & 0.23 & $<0.12$ & 0.27 & 0.09 & $<0.01$ \\
\hline & $1-\mathrm{S} 4$ & & 0.06 & 0.22 & $<0.12$ & 0.24 & 0.11 & $<0.01$ \\
\hline & \multirow{2}{*}{$1-W$} & $\min$. & 0.02 & 0.3 & 0.14 & 0.41 & 0.15 & 0.06 \\
\hline & & $\max$. & 0.08 & 0.47 & 0.36 & 0.81 & 0.17 & 0.11 \\
\hline & \multirow{2}{*}{$1-\mathrm{M}$} & $\min$. & 0.56 & 0.95 & $<0.12$ & 2.01 & 0.64 & 0.12 \\
\hline & & $\max$. & 0.94 & 1.65 & $<0.12$ & 4.16 & 1.04 & 0.22 \\
\hline \multirow{8}{*}{2} & 2-S1 & & 0.11 & 1.37 & 0.56 & 0.76 & 0.21 & 0.11 \\
\hline & $2-\mathrm{S} 2$ & & 0.08 & 1.97 & 0.32 & 0.61 & 0.17 & $<0.01$ \\
\hline & $2-\mathrm{S} 3$ & & 0.03 & 0.19 & $<0.12$ & 0.18 & 0.01 & $<0.01$ \\
\hline & 2-S4 & & 0.04 & 0.18 & $<0.12$ & 0.15 & 0.03 & 0.01 \\
\hline & \multirow{2}{*}{$2-W$} & $\min$. & 0.03 & 0.55 & $<0.12$ & 0.46 & 0.75 & 0.09 \\
\hline & & $\max$ & 0.05 & 0.75 & $<0.12$ & 0.91 & 0.89 & 0.15 \\
\hline & \multirow{2}{*}{ 2-M } & $\min$. & 0.44 & 0.69 & $<0.12$ & 1.24 & 0.68 & 0.1 \\
\hline & & $\max$. & 0.68 & 1.17 & $<0.12$ & 2.76 & 0.93 & 0.18 \\
\hline \multirow{8}{*}{3} & 3-S1 & & 0.04 & 0.07 & $<0.12$ & 2.28 & 0.15 & 0.13 \\
\hline & $3-\mathrm{S} 2$ & & 0.06 & 0.53 & $<0.12$ & 1.29 & $<0.06$ & $<0.01$ \\
\hline & $3-\mathrm{S} 3$ & & 0.02 & 0.18 & $<0.12$ & 0.14 & $<0.06$ & 0.02 \\
\hline & 3-S4 & & 0.02 & 0.17 & $<0.12$ & 0.07 & $<0.06$ & 0.01 \\
\hline & \multirow{2}{*}{$3-W$} & $\min$. & 0.02 & 0.38 & $<0.12$ & 0.55 & 0.77 & 0.11 \\
\hline & & $\max$. & 0.07 & 0.98 & $<0.12$ & 0.95 & 1.06 & 0.14 \\
\hline & \multirow{2}{*}{$3-\mathrm{M}$} & $\min$. & 0.5 & 0.47 & $<0.12$ & 0.9 & 0.5 & 0.08 \\
\hline & & $\max$. & 0.56 & 0.66 & $<0.12$ & 1.66 & 0.67 & 0.14 \\
\hline \multirow{8}{*}{4} & 4-S1 & & 0.1 & 2.81 & $<0.12$ & 1.63 & 0.09 & 0.13 \\
\hline & 4-S2 & & 0.14 & 0.43 & $<0.12$ & 3.58 & $<0.06$ & $<0.01$ \\
\hline & 4-S3 & & $<0.02$ & 0.13 & $<0.12$ & 0.14 & $<0.06$ & $<0.01$ \\
\hline & 4-S4 & & 0.04 & 0.13 & $<0.12$ & $<0.04$ & $<0.06$ & $<0.01$ \\
\hline & \multirow{2}{*}{$4-W$} & $\min$. & $<0.02$ & 0.42 & $<0.12$ & 0.29 & 0.58 & 0.09 \\
\hline & & $\max$. & 0.09 & 1.26 & $<0.12$ & 5.23 & 0.82 & 0.17 \\
\hline & \multirow{2}{*}{ 4-M } & $\min$. & 0.08 & 0.47 & $<0.12$ & 1.08 & 0.23 & 0.16 \\
\hline & & $\max$. & 1.04 & 7.49 & 0.17 & 11.64 & 0.86 & 0.18 \\
\hline \multirow{8}{*}{5} & 5-S1 & & 0.06 & 0.13 & $<0.12$ & 0.16 & 0.18 & 0.08 \\
\hline & $5-\mathrm{S} 2$ & & 0.14 & 0.12 & $<0.12$ & 0.16 & $<0.06$ & $<0.01$ \\
\hline & $5-\mathrm{S} 3$ & & $<0.02$ & 0.09 & $<0.12$ & 0.09 & $<0.06$ & $<0.01$ \\
\hline & $5-\mathrm{S} 4$ & & 0.03 & 0.1 & $<0.12$ & $<0.04$ & $<0.06$ & $<0.01$ \\
\hline & \multirow{2}{*}{$5-W$} & $\min$. & 0.01 & 0.25 & $<0.12$ & $<0.04$ & 0.25 & 0.01 \\
\hline & & $\max$. & 0.05 & 0.69 & $<0.12$ & 0.22 & 0.26 & 0.06 \\
\hline & \multirow{2}{*}{$5-\mathrm{M}$} & $\min$. & 0.06 & 0.27 & $<0.12$ & 0.64 & 0.22 & 0.06 \\
\hline & & $\max$. & 0.74 & 0.61 & $<0.12$ & 1.44 & 0.27 & 0.08 \\
\hline
\end{tabular}

*Fraction refers to a production stage, $\mathrm{S} 1-\mathrm{S} 4$ are incineration procedures, $\mathrm{W}$ is shaking procedure, $\mathrm{M}$ is mixing procedure 
tions in S3 and S4 were observed in comparison with S1 and S2. Metal concentrations in S1 were from minimum $10 \%$ to maximum $500 \%$ higher than those observed in S3 and S4. Especially in the case of manganese, one can observe that only the S1 and S2 incineration procedures allow for metal extraction above the determination limit of the applied analytical technique. Moreover, also in the fraction samples, a positive correlation between time and effective extraction can be observed.

In fraction 3, higher effectiveness of mixing and shaking was observed in comparison with incineration - the process dedicated to the procedure of vegetable oil sample preparation for determination of metals. The same can be observed in fraction 2 for iron, cadmium, and lead. Copper concentration is especially high; minor differences in maximum and minimum concentrations during mixing in raised temperature were observed. The minimal value is 0.50 $\mathrm{mg} / \mathrm{kg}$, and maximum $0.56 \mathrm{mg} / \mathrm{kg}$, and these are the values from $1,250 \%$ to $1,400 \%$ higher than the concentration values of this metal in S1.

This can be explained by the contamination of samples and the effect of the matrix, which are characteristic for the first stage of material refining. The concentration of $\mathrm{Mn}$ below the determination limit for each procedure is also characteristic. According to Radziemska et al., the average $\mathrm{Fe}$ concentration in this fraction was $2.15 \mathrm{mg} / \mathrm{kg}$. Low $\mathrm{Fe}$ concentration in the $\mathrm{S} 2$ sample $(1.29 \mathrm{mg} / \mathrm{kg})$ may indicate that the error was made by the analyst and will be the subject of further studies.

Whitened oil in fraction 4 is characterized by higher concentrations of heavy metals and Fe and Mn in samples S1 and S2, as well as maximal values for the procedures of shaking and mixing. This is most noticeable in the case of copper, where maximal concentration of mixing in raised temperatures is $1,040 \%$ higher than for the $\mathrm{S} 1$ concentration. This is justified due to the high temperatures used in the production stage. During this stage, iron concentration increases in particular, and Mmax concentration is higher by about $1,000 \%$ in comparison to $\mathrm{S} 1$, and this is the main contaminant among metals. Similarly to fraction 3 (also in fraction 4), manganese occurs below the determination limit. Its determination was successful only in the procedure of mixing at longer extraction time (maximal value is $0.17 \mathrm{mg} / \mathrm{kg}$ ).

Reduced pressure is favorable for the removal of heavy metals from oil, which is why the final product, fraction 5, which gets to the market, is characterized by low concentrations of metals and small differences between minimal and maximal values of these concentrations. The exception is the maximal value of copper concentration in the procedure of mixing, higher by more than $1,200 \%$ than the minimal concentration value. Manganese concentration remained below the determination limit $<0.12 \mathrm{mg} / \mathrm{kg}$. According to Radziemska, the average concentration of Fe is $0.66 \mathrm{mg} / \mathrm{kg}$, while in the studied samples it was $0.16 \mathrm{mg} / \mathrm{kg}$ for S1 and S2, which indicates good quality of the investigated oil.

In the summary of the study, the variability of concentration of a given metal during the whole production of rapeseed oil was analyzed.

A similar trend of concentration variability in particular samples of production fractions was observed for all three methods of sample preparation. However, it should be underlined that higher total concentrations of metals were
$\mathrm{Cu}$ concentration

in fractions $1-5[\mathrm{mg} / \mathrm{kg}]$

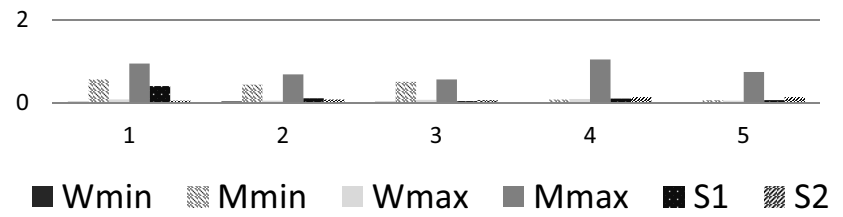

Zn concentration in fractions $1-5[\mathrm{mg} / \mathrm{kg}]$

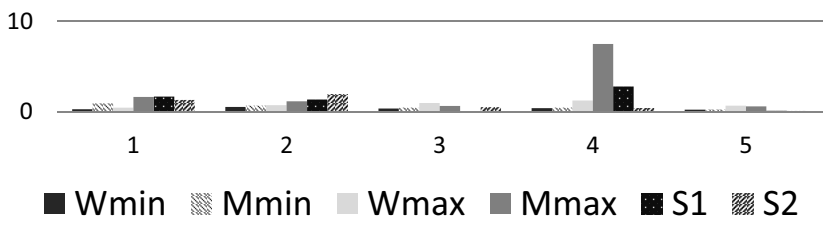

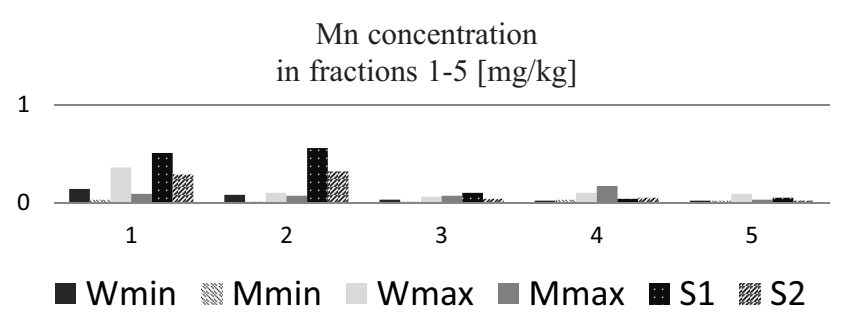

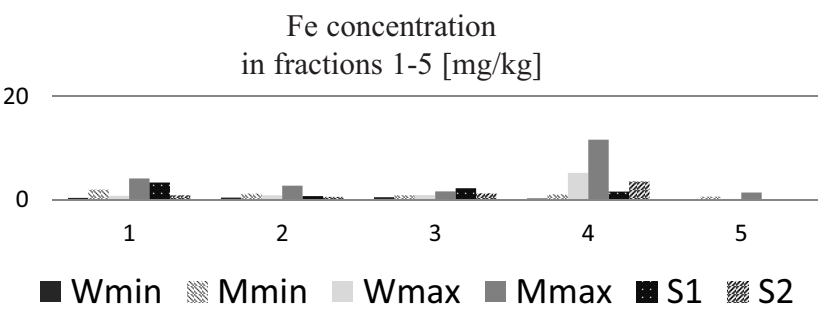

$\mathrm{Pb}$ concentration in fractions $1-5[\mathrm{mg} / \mathrm{kg}]$

2
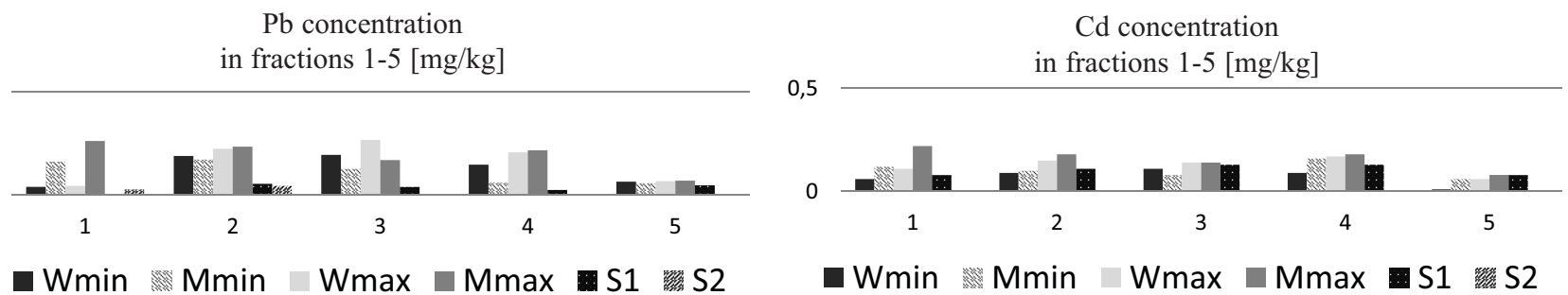

Fig. 1. Comparison of metal concentrations using particular extraction techniques. 
always determined in S1 rather than S2. Therefore, a conclusion can be drawn that in a porcelain melting pot the rinsing of metals from the walls and contamination of samples occurred. $\mathrm{Zn}$ and $\mathrm{Fe}$ were the dominating metals in particular production fractions.

It is also noteworthy that in spite of finding this phenomenon in fractions constituting semi-products, the final fraction - meant for consumption - contained the lowest concentrations of metals in comparison with other fractions, with the exception of lead in the $\mathrm{S} 1$ sample prepared in a porcelain melting pot. This concentration exceeded the permissible limits defined in the Commission Directive (EC) and amounted to $0.18 \mathrm{mg} / \mathrm{kg}$.

\section{Conclusions}

The selected procedures of preparing oil samples using the incineration method allowed for the reduction of extraction time from $12 \mathrm{~h}$ to $5.5 \mathrm{~h}$, and for the elimination of organic reagents. It was found that the two-stage incineration of samples is necessary. Limiting the procedure to a single incineration of samples drastically reduces its effectiveness. Moreover, it seems justifiable to use a platinum melting pot. In a porcelain pot the contaminants are rinsed off to the analyte, which considerably disturbs the results.

The possibility to apply classical extraction methods is disputable. The extraction effectiveness by sole dissolution with acid and mixing the sample is ineffective and cannot be applied in the determination of vegetable oil. The method aided by temperature seems attractive as the increase in temperature significantly improves the effectiveness of extraction. It was found that the extraction time positively influences its effectiveness as total time of sample preparation corresponds with the time of preparation of samples S1 and S2. The reduced amount of analyte is a disadvantage caused by a fragmentary separation of acid and oil phase. A similar trend of concentration variability of determined metals was observed in particular samples of production fractions for each of the sample preparation methods. $\mathrm{Zn}$ and Fe dominated in particular production fractions. The technology used in oil production effectively removes heavy metals $-\mathrm{Fe}$ and $\mathrm{Mn}$ - from the raw material.

\section{References}

1. ANWAR F., KAZI T.G., SALEEM R., BHANGER M.I. Rapid Determination of some trace metals in several oils and fats. Grasas Aceites. 2, 160, 2004.

2. JUSZCZAK L. Chemical contamination of food and methods of their determination. Lab Przem. 3, 38, 2008 [In Polish].

3. DARRACQ S., BERNHARD-BITAUD C., BOURRIE B., EVRARD J., BURGHART P., PAGES X., LACOSTE F. Heavy metals transfer from soil to rapeseed oil. Sustainable Organic Waste Management for Enviromental Protection and Food Safety - Conference material. 61, 2004.
4. CHAVES E. S., DOS SANTOS E.J., ARAUJO R. G.O., OLIVEIRA J.V., FRESCURA V.L.A., CURTIUS A.J. Metals and phosphorus determination in vegetable seeds used in the production of biodiesel by ICP OES and ICPMS. Microchem. J. 96, 71, 2010.

5. SZYCZEWSKI P., NIEDZIELSKI P., SOBCZYŃSKI T., SIEPAK J. Heavy metals in Poland. Pol. J. Environ. Stud. 18, (5), 755, 2009.

6. ANGELOVA V., IVANOVA R., IVANOV K. Heavy metal accumulation and distribution in oil crops, Commun. Soil. Sci. Plan. 35, 2551, 2005.

7. ZIOŁA-FRANKOWSKA A., FRANKOWSKI M., SZYCZEWSKI P. Determination of heavy metals in vegetable oils. Lab. 5-6, 58, 2011.

8. CYPRIANO J.C., COSTA MATOS M.A., MATOS R.C. Ultrasound-assisted treatment of palm oil samples for the determination of copper and lead by stripping chronopotentiometry. Microchem. J. 90, 26, 2008.

9. Commission Directive (EC) 1881/2006 of 19.12.2006 year on the highest permissible contamination levels in foods, 2006.

10. DUGO G., LA PERA L., LA TORRE G.L., GIUFFRIDA D. Determination of $\mathrm{Cd}(\mathrm{II}) \cdot \mathrm{Cu}(\mathrm{II}) . \mathrm{Pb}(\mathrm{II})$. and $\mathrm{Zn}$ (II) content in commercial vegetable oils using derivative potentiometric stripping analysis. Food Chem. 87, 639, 2004.

11. DE LEONARDIS A., MACCIOLA V., DE FELICE M. Copper and iron determination in edible vegetable oils by graphite furnace atomic absorption spectrometry after extraction with diluted nitric acid. Int. J. Food Sci. Tech. 35, 371, 2000.

12. GHAEDI M., SHOKROLLAHI A., KIANFAR A.H., MIRSADEGHI A.S., POURFAROKHI A., SOYLAK M. The determination of some heavy metals in food samples by flame atomic absorption spectrometry after their separationpreconcentration on bis salicyl aldehyde. 1.3 propan diimine (BSPDI) loaded on activated carbon. J. Hazard. Mater. 154, 128, 2008.

13. CHEMAT S., LAGHA A., AMAR H.A., CHEMAT F. Ultrasound assisted microwave digestion. Ultrason. Sonochem. 11, 5, 2004.

14. GAN J., PAPIERNIK S.K., KOSKINEN W.C., YATES S.R. Evaluation of Accelerated Solvent Extraction (ASE) for Anaysis of PesticideResidues in Soil. Environ. Sci. Technol., 33, (18), 3249, 1999.

15. SPIRIC A., TRBOVIC D., VRANIC D., DJINOVIC J., PETRONIJEVIC R., MATEKALO-SVERAK V. Statistical evaluation of fatty acid profile and cholesterol content in fish (common carp) lipids obtained by different sample preparation procedures. Anal. Chim. Acta. 672, 66, 2010.

16. ANSARI R., KAZI T.G., JAMALI M.K., ARAIN M.B., SHERAZI S.T., JALBANI N., AFRIDI H.I. Improved extraction method for the determination of iron. copper and nickel in new varieties of sunflower oil by atomic absorption spectroscopy. J. AOAC Int., 91, 400, 2008.

17. MENDILA D., ULUÖZLÜA O.D., TÜZENA M., SOYLAK M. Investigation of the levels of some element in edible oil samples produced in Turkey by atomic absorption spectrometry. J. Hazard. Metal. 165, 724, 2009.

18. RADZIEMSKA E., LEWANDOWSKI W., SZUKALSKA E., TYNEK M., PUSTELNIK A., CIUNEL K. Biofuels from rape. Preparation of raw materials to obtain biodiesel in farm conditions and the pilot methanolysis, CDEM 1-2, 79, 2009 [In Polish]. 